\title{
Indeks Tingkat Pelayanan Jalan Berbasis Model Linier di Ruas Jalan Raya Kertajaya Indah Surabaya
}

\author{
Hendrata Wibisana \\ Staft Pengajar Program Studi Teknik Sipil UPN Veteran Jatim \\ email: hw00198@yahoo.com; hendrata2008@gmail.com
}

\begin{abstract}
ABSTRAK
Pertumbuhan jumlah kendaraan di kota Surabaya seiring dengan pertumbuhan jumlah penduduk, dan sebagai salah satu kota yang memiliki kepadatan penduduk yang cukup tinggi sekitar 3 juta jiwa, maka kepemilikan kendaraan juga cukup besar. Hal ini juga ditunjang dengan pertumbuhan perekonomian yang cukup tinggi. Seiring dengan itu pula ruas jalan yang ada di kota Surabaya membutuhkan peningkatan dan pengawasan yang besar, karena dengan jumlah volume lalu lintas yang tinggi, menuntut kapasitas dan kapabilitas dari ruas jalan yang tersedia, terutama jalan arteri yang rata-rata padat kendaraan. Penelitian ini mengambil ruas jalan KERTAJAYA INDAH di kota Surabaya sebagai sampel, karena ruas jalan ini memiliki volume kendaraan yang cukup tinggi. Penelitian ini dimaksudkan hendak menghitung nilai kapasitas dan indeks pelayanan jalan dengan menggunakan metode regresi linier, dan dari hasil perhitungan yang ada diperoleh nilai kapasitas jalan sebesar $=7270,56 \mathrm{smp} / \mathrm{jam}$ dan indeks tingkat pelayanan (a) sebesar $=0,75$. Dengan nilai ini maka dapat dikatakan bahwa jalan Kertajaya Indah memiliki tingkat kejenuhan yang cukup tinggi, dimana MKJ I mensyaratkan harga derajad kejenuhan maksimum adalah 0,8.
\end{abstract}

Kata Kunci: Indeks Tingkat Pelayanan, Kapasitas Jalan, Volume lalu lintas

\section{PENDAHULUAN}

\subsection{Latar Belakang Masalah}

Surabaya merupakan salah satu kota terbesar di Indonesia, dan sebagai kota yang besar dengan ditandai jumlah penduduk sekitar 3 juta jiwa, Surabaya merupakan kota yang memiliki kehidupan perekonomian yang baik, dan dengan aktifitas ekonomi yang baik dan dengan ditunjang oleh adanya sarana dan prasarana yang baik pula maka distribusi pergerakan juga mengalami perkembangan yang cukup signifikans sejalan dengan pertumbuhan jumlah kendaraan.

Dari beberapa observasi awal yang telah dilakukan terlihat bahwa pertumbuahn pergerakan akibat aktifitas ekonomi di beberapa tempat tidak merata. Ada suatu daerah yang memiliki jumlah pergerakan yang rendah tetapi sebaliknya ada daerah yang melebihi kapasitas dari prasarana jalan yang sudah dibuat. Hal ini dapat dimengerti karena pertumbuhan ekonomi belum tersebar merata di semua area di kota Surabaya, sehingga daerah yang memiliki pusat konsentrasi ekonomi akan memiliki jumlah pergerakan yang tinggi pula, dengan kata lain akses menuju pusat ekonomi meningkat.
Ruas jalan yang memiliki kelebihan beban akan menimbulkan beberapa permasalahan yang cukup serius, dimana dengan jumlah pergerakan kendaraan yang meningkat akan berakibat kemacetan, sering terjadi kecelakaan serta adanya polusi udara yang merugikan kesehatan. Ruas jalan akan mengalami kemacetan apabila kapasitas dari badan jalan tersebut tidak mencukup untuk volume atau arus yang melalui ruas jalan per jamnya., dengan kata lain volume lalu lintas melebihi kapasitas jalan yang ada.

Pada penelitian ini hendak diteliti seberapa besar nilai kapasitas dari ruas jalan di Kertaj aya Indah kota Surabaya serta indeks pelayanan jalan yang ada di ruas jalan tersebut.

\subsection{Permasalahan}

Dengan melihat kepada latar belakang masalah yang ada maka dapat diperoleh permasalahan yang akan dicari solusi pemecahannya :

Berapakah indeks tingkat pelayanan jalan yang ada pada ruas jalan raya Kertajaya Indah di kotamadya Surabaya?. 
Berapakah nilai kapasitas jalan raya KERTAJ AYA INDAH yang ada saat ini ?

\subsection{Tujuan Penelitian}

Penelitian ini bertujuan untuk :

Menghitung berapakah nilai indeks pelayanan jalan pada ruas jalan raya Kertajaya Indah di kotamadya Surabaya

Mencari nilai kapasitas C dari ruas jalan raya Kertajaya Indah kotamadya Surabaya.

\subsection{Batasan Penelitian}

Penelitian ini dibatasi dengan mengambil sample pengukuran hanya pada ruas jalan arteri Kertajaya Indah kotamadya Surabaya, dengan waktu pengukuran pagi hari jam 08.00 - 10.00 WIB. Kendaraan yang diukur adalah kendaraan bermotor, dan tidak menghitung hambatan samping yang ada. Perhitungan kapasitas menggunakan Manual Kapasitas J alan Indonesia (MKJ I).

\subsection{Manfaat Penelitian}

Penelitian ini dapat dimanfaatkan sebagai kajian dasar mengenai studi kapasitas dan pengukuran indeks pelayanan jalan, dan dapat dilanjutkan untuk penelitian yang lebih luas dalam rekayasa lalu lintas, disamping itu juga memberikan masukan kepada aparat yang berwenang sebagai bahan acuan untuk mengambil keputusan tentang kondisi jalan di Kertajaya Indah kota Surabaya.

\section{TINJ AUAN PUSTAKA}

\subsection{Karakteristik Arus dan Komposisi Lalu Lintas}

Arus atau volume lalu lintas pada suatu jalan diukur berdasarkan jumlah kendaraan yang melewati titik tertentu selama waktu tetentu. Dalam beberapa hal lalu lintas dinyatakan dengan "lalu lintas harian ratarata per tahun" yang disebut AADT (Average Annual Daily Traffic) atau"lalu lintas harian rata-rata (LHR) bila periode pengamatannya kurang dari 1 tahun.
Arus Ialu lintas pada suatu lokasi tergantung pada beberapa faktor yang berhubungan dengan kondisi daerah setempat. Besaran ini sangat bervariasi pada tiap jam dalam sehari, pada tiap hari dalam seminggu dan pada tiap bulan dalam setahun.

Nilai arus lalu lintas (Q) mencerminkan komposisi lalu lintas dengan menyatakan arus dalam satuan mobil penumpang (smp). Semua nilai arus lalu lintas (per arah dan total) diubah menjadi satuan mobil penumpang (smp) dengan menggunakan ekivalensi, mobil penumpang (smp) yang diturunkan secara empiris untuk type kendaraan (Manual Kapasitas Jalan Indonesia, Direktorat Jendral Bina Marga, Febuari 1992) sebagai berikut :

1. Kendaraan ringan (LV) termasuk mobil penumpang, minibus, truck, pick up dan jeep.

2. Kendaraan berat (HV) termasuk truck dan bus.

3. Sepeda motor.

\subsection{Arus Lalu Lintas Dinamis}

Arus lalu lintas berinteraksi dengan sistem jaringan transportasi. Jika arus lalu lintas meningkat pada ruas jalan tertentu, waktu tempuh pasti bertambah (karena kecepatan menurun). Arus maksimum yang dapat melewati suatu ruas jalan biasa disebut kapasitas ruas jalan tersebut. Arus maksimum yang dapat melewati suatu titik (biasanya pada persimpangan dengan lampu lalu lintas) biasa disebut arus jenuh.

Kapasitas ruas jalan perkotaan biasanya dinyatakan dengan kendaraan (atau dalam Satuan Mobil Penumpang/SMP) per jam. Hubungan antara arus Dengan waktu tempuh (atau kecepatan) tidaklah linier. Penembahan kendaraan tertentu pada saat arus rendah akan menyebabkan penambahan waktu tempuh yang kecil jika dibandingkan dengan penambahan kendaraan paa saat erus tinngi.

Terlihat pada kurva mempunyai asimtot pada saat arus mencapai kapasitas (atau nilai nisbah Volume per Kapasitas/NVK mandekati satu). Secara sederhana, 
kapasitas tak akan pernah tercapai dan waktu tempuh akan meningkat pesat pada saat arus lalu lintas mendekati kapasitas. Secara realita,arus tidak akan beroprasi denagn kondisi sederhana ini.

Oleh sebab itu, modifikasi terhadap teori dasar harus dilakukan. Jika arus lalu lintas mendekati kapasitas, kemacetan mulai terjadi. Kemacetan semakin meningkat apabila arus begitu besarnya sehingga kendaraan sangat berdekatan satu sama lain. Kemacetan total terjadi apabila kendaraan harus berhenti atau bergerak sangat lambat.

\subsection{Hubungan Arus Lalu Lintas dengan Waktu Tempuh}

Besarnya waktu tempuh pada suatu ruas jalan sangat tergantung dari besarnya arus dan kapasitas ruas jalan tersebut. Hubungan antara arus dengan waktu tempuh dapat dinyatakan sebagai suatu fungsi dimana jika arus bertambah maka waktu tempuh juga akan bertambah. Menurut Davidson (1966), hal ini sebenarnya merupakan konsep dsar dalam teori antrian yang menyatakan bahwa tundaan yang terjadi pada tingkat kedatangan dan tingkat pelayanan yang tersebar secara acak dapat dinyatakan sebagai persamaan (1) berikut:

$$
\begin{aligned}
\mathrm{W}_{\mathrm{Q}} & =\frac{P^{2}}{[\lambda(1-\rho)]} \\
\mathrm{W}_{\mathrm{Q}} & =\text { Tundaan per kendaraan } \\
\lambda & =\text { Tingkat kedatangan } \\
\rho & =\frac{\lambda}{\mu} \\
\mu & =\text { Tingkat pelayanan }
\end{aligned}
$$

Berdasarkan teori antrian stokastik untuk satu tempat pelayanan dengan sebaran pelayanan acak, besarnya waktu tunggu yang dialami oleh setiap kendaraan dengan sebaran kedatangan acak dapat dinyatakan dengan persamaan (2) berikut:

$$
\mathrm{E}_{\mathrm{w}}=\frac{\rho}{[\mu(1-\rho)]}
$$

Karena $\quad \mu=\frac{\lambda}{\rho}$ maka sebenarnya persamaan (2) sama dengan persamaan (1)

Konsep antrian dalam waktu pelayanan merujuk pada waktu minimum yang dibutuhkan kendaraan untuk melalui suatu ruas jalan sesuai dengan tingkat pelayanan jalan yang ada. Waktu pelayanan adalah waktu tempuh yang dibutuhkan ketika tidak ada kendaraan lain pada jalan tersebut (kondisi arus bebas), sehingga tundaan antrian dapat dipertimbangkan sebagai pertambahan waktu tempuh akibat adanya kendaraan lain yang dapat dinyatakan sebagai berikut.

$$
\begin{aligned}
& \text { Waktu tempuh }=\text { waktu pelayanan }+ \\
& \text { tundaan }
\end{aligned}
$$

Nilai nisbah tundaan antrian dengan waktu pelayanan dapat diturunkan dengan urutan persamaan (4) - (5) sebagai berikut:

$$
\begin{aligned}
& \frac{W_{Q}}{1 / \mu}=\frac{\rho^{2 \mu}}{[\lambda(1-\rho)]} \\
& \frac{W_{Q}}{1 / \mu}=\frac{\rho}{[(1-\rho)]}
\end{aligned}
$$

J ika waktu pelayanan adalah waktu tempuh pada kondisi arus bebas (To) maka persamaan (5) dapat dinyatakan dengan bentuk lain seperti persamaan (6) - (7) berikut.

$$
\frac{W_{Q}}{T_{0}}=\frac{\rho}{[(1-\rho)]}
$$




$$
\mathrm{W}_{\mathrm{Q}}=T_{0 .} \cdot \frac{\rho}{[(1-\rho)]}
$$

Tundaan yang terjadi disebabkan oleh satu rangkaian antrian sehingga variasi pada waktu tempuh tergantung pada tundaan antrian. Oleh karena itu, persamaan (7) harus dimodifikasi dengan memasukkan suatu faktor 'a' (indeks tingkat pelayanan) yang besarnya tergantung dari karakteristik ruas jalan dan tundaan akibat adanya kendaraan lain pada ruas jalan tersebut sehingga dihasilkan persamaan (8) berikut.

$$
\mathrm{W}_{\mathrm{Q}}=T_{0 .} \cdot \frac{\rho}{[(1-\rho)]}
$$

Selanjutnya, dengan memasukkan persamaan (8) ke persamaan (3), maka dihasilkan urutan persamaan (9)-(12) berikut ini.

$$
\begin{aligned}
& \mathrm{T}_{\mathrm{Q}}=\mathrm{T}_{0}+\mathrm{W}_{\mathrm{Q}} \\
& \mathrm{T}_{\mathrm{Q}}=\mathrm{T}_{0}+a \cdot \frac{\rho}{[(1-\rho)]} \\
& \mathrm{T}_{\mathrm{Q}}=T_{Q}\left[1+a \frac{\rho}{(1-\rho)}\right] \\
& T_{Q}=T_{0}\left[\frac{1-(1-a) \rho}{1-\rho}\right]
\end{aligned}
$$

Dengan mengasumsikan $\rho=\frac{Q}{C}=$ maka persamaan (12) dapat ditulis kembali sebagai persamaan (13) berikut yang biasa disebut persamaan Davidson. Secara matematis, ciri tersebut dapat dinyatakan sebagai berikut:

$$
T_{Q}=T_{0}\left[\frac{1-(1-a) \frac{Q}{C}}{1-\frac{Q}{C}}\right]
$$

$\mathrm{T}_{\mathrm{Q}}=$ Waktu tempuh pada saat arus $=\mathrm{Q}$ (kondisi arus bebas)
$\mathrm{Q}=$ Arus lalu lintas

$\mathrm{C}=$ Kapasitas

$\mathrm{a}=$ indeks tingkat pelayanan/ ITP (fungsi dari faktor-faktor yang menyebabkan keragaman dalam arus, seperti: parkir, penyeberang jalan, gangguan samping, lebar jalan, jumlah lajur, tipe perkerasan, tanjakan, turunan, dan lain-lain).

Dalam banyak kajian transportasi, terdapat beberapa pendekatan sederhana yang digunakan untuk memperoleh nilai ' $a$ ' (indeks tingkat pelayanaan) untuk suatu ruas jalan.

\subsection{Pendekatan Linear}

Persamaan (2.13) dapat disederhanakan dengan urutan penyederhanaan seperti tertulis pada persamaan (14)-(16).

$$
\begin{aligned}
& \frac{T_{Q}}{T_{0}}=1+\frac{a\left(\frac{Q}{C}\right)}{1-\left(\frac{Q}{C}\right)} \\
& \frac{T_{Q}}{T_{0}}=1+a \frac{Q}{C-Q} \\
& T_{Q}=T_{0}+a T_{0} \frac{Q}{C-Q}
\end{aligned}
$$

Dengan melakukan transformasi linear, persamaan (16) dapat disederhanakan dan ditulis kembali sebagai persamaan linier $Y_{i}=$ $\mathrm{A}+\mathrm{X}_{\mathrm{i}}$ dengan mengasumsikan $T_{Q}^{i}=Y_{i}$ dan $\frac{Q i}{C-Q i}=X i$. Dengan mengetahui beberapa set data $T_{Q}^{i}$ dan $Q_{i}$ yang bisa didapat dari survey waktu tempuh dan volume arus lalu lintas, maka dengan menggunakan analisa regresi linear (persamaan 17 dan 18), parameter A dan B dapat dihitung dan dihasilkan beberapa nilai berikut: $\mathbf{A}=$ To dan $\mathbf{B}=$ aTo sehingga 
nilai indeks tingkat pelayanan (ITP) adalah $\mathbf{a}=\mathbf{B} / \mathbf{A}$.

$$
\begin{gathered}
B=\frac{N \sum_{i=l}^{N}(X i Y i)-\sum_{i=l}^{N}\left(X_{i}\right) \sum_{i=l}^{N}\left(Y_{i}\right)}{N \sum_{i=l}^{N}\left(X_{i}\right)^{2}-\left[\sum_{i-l}^{N}\left(X_{i}\right)\right]^{2}} \\
A=\overline{-}-\overline{B X}
\end{gathered}
$$

$\bar{Y}$ dan $\bar{X}$ adalah nilai rata-rata $\mathrm{Y}_{\mathrm{i}}$ dan $\mathrm{X}_{\mathrm{i}}$

\subsection{Perhitungan Kapasitas Ruas J alan}

Kapasitas didefinisikan sebagai arus maksimum melalui suatu titik di jalan yang dapat dipertahankan persatuan jam pada kondisi tertentu, tetapi untuk jalan dua lajur dua arah, kapasitas ditentukan untuk arus dua arah (kombinasi dua arah), tetapi untuk jalan dengan banyak lajur, arus dipisahkan per arah dan kapasitas ditentukan per lajur. Kapasitas untuk kondisi sesungguhnya (C) dapat ditentukan dengdn mengalikan faktor - faktor yang sudah disesuaikan dengan tabel yang ada dari buku Manual Kapasitas J alan Indonesia adalah sebagai berikut :

$\mathrm{C}=\mathrm{Co} \times \mathrm{FClv}{ }^{x} \mathrm{FC}_{\mathrm{SP}} \mathrm{xFCspxFCcs}$ (smp/jam)

Dimana :

$\mathrm{C}=$ Kapasitas (smp/ jam).

Co = Kapasitas dasar ( smp/ jam).

FCW = Faktor koreksi kapasitas untuk lebar jalan.

$\mathrm{FC}_{\mathrm{SP}}=$ Faktor koreksi kapasitas akibat pembagian arah (tidak berlaku untuk jalan satu arah ).

$\mathrm{FC}_{\mathrm{SF}}=$ Faktor koreksi kapasitas akibat gangguan samping.

$\mathrm{FC}_{\mathrm{CS}}=$ Faktor koreksi kapasitas akibat ukuran kota.

\section{METODE PENELITIAN}

\subsection{Pengumpulan Data}

Pada penelitian ini data-data yang dikumpulkan adalah data lapangan di ruas jalan Kertajaya Indah, dimana data tersebut meliputi :

Pengukuran kecepatan kendaraan bermotor yang melintas

Pengukuran Volume kendaraan bermotor

Mengukur lebar jalan efektif

Mencari nilai Co, FCw, FCsp, FCsf, FCcs dari Tabel MKJ I tahun 1977 untuk mendapatkan nilai kapasitas $\mathrm{C}$.

\subsection{Menghitung Kecepatan Kendaraan}

Kecepatan kendaraan yang diukur adalah kecepatan kendaraan bermotor dengan cara mengambil 3 buah sampel kendaraan selang waktu 10 menit dan kemudian dilakukan perhitungan rata-rata kecepatan.

Alat ukur untuk menghitung kecepatan kendaraan adalah stop watch digital merk Alba.

\subsection{Menghitung Volume Kendaraan}

Volume kendaraan yang dihitung adalah kendaraan bermotor yang melintas ruas jalan Kertajaya Indah selama 10 menit, untuk kemudian dilakukan pengulangan pengukuran selama kurun waktu 1 jam, diperoleh 6 buah data masukan.

Alat ukur yang digunakan untuk menghitung volume adalah counting checker atau hand tally.

\subsection{Menghitung Waktu Tempuh}

Waktu tempuh dari kendaraan dihitung dengan cara sebagai berikut :

Digunakan rumus dasar : $\mathrm{S}=\mathrm{V} \times \mathrm{t}$

Dimana $\mathrm{S}$ adalah jarak atau panjang ruas jalan Kertajaya Indah, satuan dari S adalah meter

$\mathrm{V}$ adalah kecepatan rata-rata kendaraan yang sudah dihitung, satuan $\mathrm{V}$ adalah 
ISSN.1907-753X

$\mathrm{km} / \mathrm{jam}$ yang dikonversi ke dalam meter/ detik

$\mathrm{t}$ adalah waktu tempuh kendaraan, satuan dari $t$ adalah detik

\subsection{Menghitung Nilai Kapasitas ( C )}

Nilai kapasitas dihitung dengan menggunakan rumus dari MKJ I 1977 sebagai berikut

$\mathrm{C}=\mathrm{Co} \times \mathrm{FCW} \times \mathrm{FCsp} \times \mathrm{FCsf} \times \mathrm{FCCS}$

Dimana :

C = kapasitas dalam satuan $\mathrm{smp} / \mathrm{jam}$

Co = kapasitas dasar dalam satuan $\mathrm{smp} / \mathrm{jam}$

$\mathrm{FCW}$ = faktor penyesuaian kapasitas untuk lebar jalur lalu lintas

FCsp = faktor penyesuaian kapasitas untuk pemisahan arah atau distribusi arah

FCsf = faktor penyesuaian kapasitas untuk hambatan samping

FCCs = faktor penyesuaian kapasitas untuk ukuran kota

\subsection{Menghitung Indeks Pelayanan J alan}

Indeks Pelayanan Jalan dihitung dengan cara sebagai berikut :

> Menetapkan waktu tempuh yang diperoleh sebelumnya dari data lapang

> Melakukan konversi menit ke dalam satuan jam

$>$ Menetapkan nilai volume lalu lintas Q dalam bentuk smp/ jam

> Melakukan perhitungan selisih nilai kapasitas $\mathrm{C}$ dengan nilai volume $\mathrm{Q}$

> Melakukan perhitungan untuk Q/ (C - Q ) dan diasumsikan sebagai nilai $X$ dalam perhitungan regresi linier

Untuk perhitungan nilai indeks pelayanan (a ) dilakukan dengan regresi linier dengan persamaan $Y=A X+B$, dimana nilai $a$ dan $b$ diperoleh dengan rumusan sebagai berikut :

$$
\begin{aligned}
A & =\frac{N \cdot \sum X i Y i-\sum X i \cdot \sum Y i}{N \cdot \sum X i{ }^{2}-\left(\sum X i\right)^{2}} \\
B & =\frac{\sum Y i}{N}-A \cdot \frac{\sum X i}{N}
\end{aligned}
$$

Jika A dan B sudah diperoleh maka bisa dihitung nilai waktu tempuh kendaraan To dan indeks a, dimana To adalah nilai intersep dari regresi atau nilai $B$, sedangkan indeks a adalah pembagian ( $\mathrm{A} / \mathrm{B}$ ) dari fungsi regresi yang didapatkan. 


\section{HASIL DAN PEMBAHASAN}

\subsection{Pengumpulan data}

Tabel 4.1. Data kecepatan kendaraan

\begin{tabular}{|c|c|c|c|c|c|}
\hline$\frac{\frac{5}{0}}{\frac{0}{0}}$ & $\begin{array}{l}\frac{5}{0} \\
\frac{0}{3} \\
\frac{5}{3} \\
\frac{8}{d} \\
\frac{8}{d}\end{array}$ & 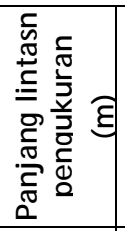 & 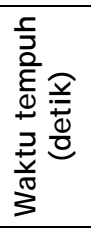 & 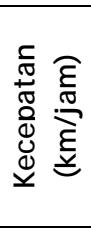 & 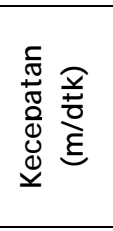 \\
\hline \multirow{6}{*}{ 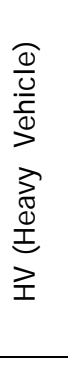 } & 1 & 50 & 6,46 & 7,74 & 27,86 \\
\hline & 2 & 50 & 6,25 & 8,00 & 28,80 \\
\hline & 3 & 50 & 4,06 & 12,32 & 44,33 \\
\hline & 4 & 50 & 6,32 & 7,91 & 28,48 \\
\hline & 5 & 50 & 4,69 & 10,66 & 38,38 \\
\hline & 6 & 50 & 3,97 & 12,59 & 45,34 \\
\hline \multirow{7}{*}{ 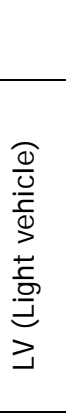 } & & & & & $\begin{array}{l}\mathrm{J} m \mathrm{ml}: \\
213,19\end{array}$ \\
\hline & 1 & 50 & 4,44 & 11,26 & 40,54 \\
\hline & 2 & 50 & 5,56 & 8,99 & 32,37 \\
\hline & 3 & 50 & 3,94 & 12,69 & 45,69 \\
\hline & 4 & 50 & 3,75 & 13,33 & 48,00 \\
\hline & 5 & 50 & 4,10 & 12,20 & 43,90 \\
\hline & 6 & 50 & 6,07 & 8,24 & 29,65 \\
\hline \multirow{7}{*}{ 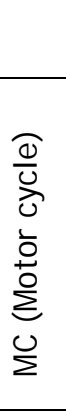 } & & & & & $\begin{array}{l}\mathrm{J} \mathrm{ml}: \\
240,15\end{array}$ \\
\hline & 1 & 50 & 3,87 & 12,92 & 46,51 \\
\hline & 2 & 50 & 6,81 & 7,34 & 26,43 \\
\hline & 3 & 50 & 5,15 & 9,71 & 34,95 \\
\hline & 4 & 50 & 3,72 & 13,44 & 48,39 \\
\hline & 5 & 50 & 4,78 & 10,46 & 37,66 \\
\hline & 6 & 50 & 4,60 & 10,87 & 39,13 \\
\hline & & & & & $\begin{array}{l}\mathrm{J} \mathrm{ml}: \\
233,07\end{array}$ \\
\hline
\end{tabular}

nama segmen jalan sekunder

lebar segmen jalan

: $10,46 \mathrm{~m}$

tipe jalan

: 4/2-D

tingkat hambatan samping

: rendah

lebar bahu jalan

: $5,55 \mathrm{~m}$

tanggal \& waktu pengukuran 2008, 08.00-10.00 WIB

menghitung kecepatan rata-rata kendaraan

$$
\begin{aligned}
S & =213,19+240,15+233,07 \\
& =686,41: 6 \\
& =114.39 \mathrm{~m} / \mathrm{dtk}
\end{aligned}
$$

Menghitung waktu tempuh kendaraan

$$
\mathrm{S}=\mathrm{V} \times \mathrm{t}
$$

$$
50 \mathrm{~m}=114,39 \mathrm{~m} / \mathrm{dtk} \times \mathrm{t}
$$$$
\mathrm{t}=50 \mathrm{~m}: 114,39 \mathrm{~m} / \mathrm{dtk}
$$$$
=0,44 \mathrm{dtk}
$$

Menghitung nilai kapasitas ( C )

$$
\begin{aligned}
C=\text { Co } & \times \text { FCW } \times \text { FCsp } \times \text { FCsf } \times \text { FCcs } \\
& =6600 \times 1,08 \times 1,00 \times 1,02 \times 1,00 \\
& =7270.56 \mathrm{smp} / \mathrm{jam}
\end{aligned}
$$

\subsection{Menghitung Indeks pelayanan jalan}

$A=\frac{6 .(0.0326)-(8.91)(0.024)}{6(11.17)-(8.91)^{2}}$

$A=0,0015$

$B=\frac{0.024}{6}-0,0015 \frac{8.91}{6}$

$B=0,02$ 
J urnal APLIKASI

ISSN. 1907-753X

TABEL 4.2. Perhitungan Tempuh Kendaraan

\begin{tabular}{|c|c|c|c|c|c|c|}
\hline TQ (detik) & TQ (jam) $=$ & $\begin{array}{c}Q \\
\text { (smp/ jam) }\end{array}$ & (C - Q) & $\begin{array}{c}\text { (Q/ C - Q) } \\
X\end{array}$ & $X * Y$ & $X 2$ \\
\hline 14,77 & 0,004 & 1936,2 & 5334,36 & 1.36 & 0.0054 & 1.85 \\
\hline 18,62 & 0,005 & 2067 & 5203,56 & 1.39 & 0.0069 & 1.93 \\
\hline 13,15 & 0,004 & 1915,2 & 5355,36 & 1.35 & 0.0054 & 1.82 \\
\hline 13,79 & 0,004 & 1965,6 & 5304,96 & 1.37 & 0.0054 & 1.87 \\
\hline 13,57 & 0,004 & 1763,4 & 5507,16 & 1.32 & 0.0053 & 1.74 \\
\hline 12,64 & 0,003 & 2098,8 & 5171,76 & 1.40 & 0.0042 & 1.96 \\
\hline 86,54 & 0.024 & 11746,2 & 31877,16 & 8.91 & 0.0326 & 11.17 \\
\hline 14,42 & 0,004 & 1957,7 & 5312.86 & 1.365 & 0.0054 & 1.86 \\
\hline
\end{tabular}

Nilai waktu tempuh kendaraan

$$
\begin{aligned}
& T_{Q}=T_{O}+a T_{o} \frac{Q}{(C-Q)} \\
& 0,024=\mathrm{TO}+0,75 \mathrm{TO} \\
& 0.024=7.68 \mathrm{TO} \\
& \text { TO }=320 \text { detik }
\end{aligned}
$$

\section{KESIMPULAN}

Indeks tingkat Pelayanan jalan raya Kertajaya Indah di kota Madya Surabaya adalah : $a=A / B$

$$
\begin{aligned}
& =0.0015 / 0.002 \\
& =0.75
\end{aligned}
$$

Sedangkan Volume di jalan raya Kertajaya Indah pada saat ini masih dapat ditampung dengan baik pada Volume $11746.2 \mathrm{smp} / \mathrm{jam}$ dengan lebar jalan 10.46 m

Dari hasil perhitungan didapatkan kapasitas jalan raya Manyar Kerto Adi adalah : $7270.56 \mathrm{smp} / \mathrm{jam}$.

\section{DAFTAR ACUAN}

Bowersoc D.J., Calabro P.J., (1981), Introduction To Transportation, Collier Macmillan, New York.

Wibisana, H, Sholichin, I, (2004), Studi Pendahuluan Pemodelan Arus Lalu Lintas di Ruas Jalan Rungkut Asri Dengan Metode Greenshield, Proceeding Seminar Nasional Perencanaan II Teknik Sipil UPN Veteran J atim, Surabaya.

Wibisana, $\mathrm{H},(2005)$, Studi Pendahuluan Pemodelan Arus Lalu Lintas di Ruas Jalan Rungkut Asri Dengan Metode Greensberg, Jurnal Rekayasa Perencanaan Vol 2. No.1, FTSP UPN Veteran J atim, Surabaya.

Wibisana, H, Wulandari, C,(2007), Analisis Tingkat Perjalanan Pada Ruas Jalan Arteri Kecamatan Rungkut Dengan Sistem Informasi Geografis, Proceeding Seminar Nasional Rekayasa Perencanaan IV, Teknik Lingkungan UPN Veteran J atim, Surabaya.

Oglesby C.H., Hicks R.G.,(1993), Teknik Jalan Raya, Edisi 4 Jilid 1, Erlangga, Jakarta 
